International Journal of Linguistics, Literature and Translation (IJLLT)

ISSN: 2617-0299 (Online); ISSN: 2708-0099 (Print)

DOI: $10.32996 / \mathrm{jjllt}$

Journal Homepage: www.al-kindipublisher.com/index.php/ijllt

\title{
A Comparative Study of Personal Pronouns, Demonstrative Pronouns and Relative Pronouns in Arabic, English and Spanish
}

Dr. Lina Ali Al-Jarrah ${ }^{1}$, Dr. Yazan Shaker Al-Mahameed*2 and Dr. Imad Abedalkareem Ababneh ${ }^{3}$

${ }^{123}$ Assistant professor, Faculty of Arts and Sciences, Amman Arab University, Jordan

Corresponding Author: Dr. Yazan Shaker Al-Mahameed, E-mail: Yazan.shaker@yahoo.com

\section{ARTICLE INFORMATION}

Received: November 01, 2020

Accepted: December 14, 2020

Volume: 3

Issue: 12

DOI: $10.32996 /$ ijllt.2020.3.12.13

\section{KEYWORDS}

Personal pronouns;

demonstrative pronouns; relative

pronouns

\section{ABSTRACT}

This study aims at conducting a comprehensive comparison of pronouns in three languages namely Arabic, English and Spanish. The comparison is implemented in light of three types of pronouns; personal pronouns, demonstrative pronouns and relative pronouns. The comparison aims chiefly at revealing areas of differences and similarities between pronouns in the three languages under investigation. The researchers compare pronouns in terms of their types, classifications and main characteristics. The comparison is accompanied with illustrative examples to enhance understanding the use of pronouns in the three languages. The needed data for the study are collected from different linguistic resources so that a detailed examination and exploration of pronouns in the three languages is made based on the collected resources. The results of analysis of pronouns reveal that pronouns in the three languages share the same referential function, which is assigning some elements to their actual referents. The analysis also depicts that the three languages act differently in terms of using those pronouns, in the sense that the differences are mostly exhibited in the pronouns specifying the number of referents, their gender and distance from referent.

\section{Introduction}

\subsection{The concept of pronouns}

Researchers in the past were concerned with pronouns through studying the linking words between the parts of a sentence, because the text consists of a number of elements where an internal net arose among them which makes a kind of harmony and cohesion among these elements, where pronouns are deemed as one of those elements.

Al-Najjar (2013) considers pronouns as an element of communication which means pronouns are anything that points to an object, a site or time...., and they are linked with the concept of indicator; as a pronoun assigns the place of a person, iden tity procedures, actions and activity.

Pronouns are also known as linguistic markers that their meaning can only be understood through context in discourse, because they are devoid of any meaning, so that pronouns are found in the mental dictionary of speakers without expressing clear meaning.

Linguists have three views regarding pronouns as explained by (Paulo as cited in Patrick, et al., 2008)

1. Pronouns are considered as linguistic expressions indicating objects, and actions of the world and used in referring to the addresser or addressee in a specific place or time. Pronouns can be regarded as a reference to distant or near object or person.

2. Pronouns are considered as referring expressions that make no differentiation between the direction and the referent.

3. Pronouns play a significant role in creating harmony in a text that help add new elements to discourse.

\footnotetext{
K C AL-KINDI CENTER

R D PEUFI OPMENT

Your gateway to world-closs research
}

Published by Al-KindiCenter for Research and Development. Copyright (c) the author(s). This is an open access article under CC BY license (https://creativecommons.org/licenses/by/4.0/) 
Pronouns is a cover term for a group of linguistic elements comprising demonstrative pronouns, relative pronouns and personal pronouns. Pronouns are linguistic markers that their referent cannot be identified unless included within the context of discourse; because they are devoid of any meaning by themselves. Therefore, Some Arab linguists in the past called them ambiguities. Ibn Yaeish (n.d) believes that pronouns are called ambiguities because they can refer to everything crosses the mind, including things that are ambiguous to the addressee, so they are ambiguous and need to be explained. Therefore, the intended meaning of ambiguities can only be understood through discourse.

Pronouns play a significant role in forming the structure of discourse and in determining the referent of the noun through their grammatical and semantic functions. The speaker uses pronouns in extended discourse between him and the addressee, so that the pronouns are used in referring to previously mentioned noun and became a part of shared information.

It is clear that a pronoun is related to the referent that is assigned to it in discourse, so that pronouns' referential function is the chief function of pronouns. The referential role of pronouns is best exhibited in assigning elements whatever so their kind, and their meaning to a former or subsequent referent in discourse.

Jacobson as cited in Barakah, (1993) considers the referential function as one of the six linguistic elements of communication. Jacobson argues that the referential function is the base for any communication as it determines the relationship between a speaker, purpose and referent and it is the most important function in the communication process itself.

The referential function makes a connection between the linguistic context and the situation; i.e., the social situation in which the linguistic utterance was said by using the referential strategy. One prominent strategy of organizing the relationship between the addresser and the addressee in discourse is politeness Maxim by Grice as cited in Cook (1989) which the speaker uses to keep a good relationship with the addressee in the sense that the speaker seeks to get on well with the addressee without annoying him. This Maxim is based on the following rules:

1. Do not Impose: It states that the addresser does not impose himself on the addressee. The addresser remains conservative and does not interfere in others affairs. This maxim implies that there must be a social distance between the addresser and the addressee.

2. Give options: This maxim states that the speaker has the power of decision so that he gives options to the addressee to tune down or remove the imposition. This maxim is best exhibited in the use of hedging, which are linguistic expressions used to mitigate the effect of speaker's utterances.

3. Make the receiver feels good: This maxim is used to reduce the imposition by apologizing about something, followed by praise to make the hearer feels good.

Taha (1998) presents a significant requirement of politeness in discourse which helps to keep communication between the two parts of discourse. He states that politeness in discourse requires the speaker to use a language that helps keep intimate relationship with the listener. He adds that the dialogue between two people is basically built on fulfilling shared purposes between the parts of discourse, so that politeness helps achieve this purpose. Based on the above-mentioned discussion on the concept of pronouns, it is fitting to indicate that the current study is conducted to gain further insight into pronouns in terms of their types and functions.

\section{Objective of the Study}

The present study aims at implementing a comprehensive comparison of pronouns in three languages; namely Arabic, Spanish and English. The comparison covers three types of pronouns in each language that is personal pronouns, demonstrative pronouns and relative pronouns.

\section{Methodology of the Study}

\subsection{Resources}

In collecting the data required for the current study, the researchers referred to various resources including books, research papers and articles. The resources that the researchers used are authored by prominent linguists in the three languages; Arabic, English and Spanish.

\section{2 procedures}

This study conducts a comprehensive comparison between pronouns in three languages; Arabic, English and Spanish. The study compares three types of pronouns: personal pronouns, demonstrative pronouns and relative pronouns. The 
comparison covers a wide range of elements related to pronouns in the three languages such as main types, characteristics, classifications. The comparison between pronouns in the three languages is accompanied with illustrative examples to enhance understanding the functions performed by those pronouns in each language.

\section{An analysis of pronouns in Arabic, Spanish and English}

This section presents three types of pronouns namely, personal pronouns, demonstrative pronouns and relative pronouns. In this section a comparison is made between those three types of pronouns in three languages; namely Arabic, Spanish and English in order to gain insight into how languages act when using pronouns.

\subsection{Personal pronouns}

Personal pronouns in Arabic are referential in nature because their reference depends completely on the context in which they are used. For instance, when saying (I am happy), the addressee specifies the referent of the pronoun (I) based on the context and in this context the pronoun (I) refers to the speaker. In some cases, the speaker produces many sentences, so that the identity of the speaker changes based on the context, however the referent of the pronoun (I) remains the same whether the speaker is a teacher, father or anybody else. Therefore, a personal pronoun is a common term in Arabic linguistics that indicates a person whether referring to a speaker, addressee or absent. Arabic Personal pronouns can be classified into two groups; First, detached pronoun, which are a stressed form of personal pronouns, used in isolation as the pronouns (Ana) I or the pronoun (Anta) you. Second, attached pronouns, which are attached to another word in the context such as the pronouns (ta or ka) in the word (darasta) you studied or (lyaka) you be aware.

Personal pronouns in Arabic can further be classified into three types according to 1- Type (masculine or feminine pronouns): masculine pronouns in Arabic are presented by the pronouns (hua, He), (Anta, You), while feminine pronouns are (Hia, She), (Anti, You) as appear in the examples below.

Example: Anta Tajm'u Alhatab

- You collect wood

Example: Anti Tajm'een Alhatab

- you Collect wood

2- Number (singular/ plural): singular pronouns in Arabic are (Hua, He), (Hia, She), (Anta, you), (Anti, You), whereas plural pronouns are (Huma, you two), (Antum, you), (hunna, they) as appear in the examples below.

Example: Antum tushahidoon Altilfaz

- You watch TV.

Example: Antuma tushahidoon Altilfaz

- You two watch TV

3- Situation (First person, second person and third person pronouns). First person pronouns in Arabic are (Ana, I) and (Nahnu, we). Second person pronouns are (Anta, you), (Antuma, you two), (Antum, you), (Anti, you), (Antunna, you). Third person pronouns are (huma, they), (hum, they), (hia, she), (hunna, they). The examples below illustrate this classification of pronouns in Arabic.

Example: Ana Atakalamu ma'a Sadiqi

- I am speaking with my friend

Example: Antum tatakmun ma'a ASadiqaiqum

- You are speaking with your friends

One further level of personal pronouns classification in Arabic can be attributed to the position of the pronoun in the sentence as follows;

1- Nominative case pronouns: Those pronouns are (Ana, I), (Nahnu, we), ( Anta, Antum, Antunna, you), (hua, he), (hia, she), (huma, you two), ( hum, they). 
2- Accusative case pronouns: those pronouns are (lyai, me), (lyana, our), (iyak, you), (lyahu,him).

Comparting to Spanish, personal pronouns in Spanish are those used to replace the subject and usually placed prior to the verb. In some cases, personal pronouns in Spanish can be omitted because the tense of the verb performs the same function of the pronoun. This case is similar to Arabic as in the sentence below

Arabic: Ayshu fee Alurdon

- I live in Jordan

Spanish: vivo en Jordania

In the two examples above in Arabic and Spanish personal pronouns are omitted and their meanings are implicitly expressed within the verb. In Spanish the first person pronoun ( yo) is used as singular personal pronoun and (Tu) is a second person pronoun used for both masculine and feminine. While, In Arabic, the pronoun (Ana, I) is used as singular first personal pronoun for both masculine and feminine and the pronoun (Nahnu, we) as plural first personal pronoun for both masculine and feminine. According to Badis, (2009), one of the most important communicative usages of the pronoun (we) is expressing solidarity with the addressee. In Contrast, Spanish uses two first person plural pronouns, one pronoun for plural feminine (Nosotras) and another for plural masculine (Nosotros) Aragonés and Palencia, (2006)

On the other hand, English language considers personal pronouns as a closed set of lexical items that plays the role of discriminating among people with respect to number, gender and animacy or other characteristics (Trask, 1993, cited in Gardelle and Sorlin 2015, p 2). In English language, there are seven personal pronouns namely I, we, you, he, she, it and they. Those personal pronouns are classified into three main categories.

1- First person pronouns comprise "I and we". Those pronouns are used to indicate the speaker, in that "I" describes singular speaker, while "we" describes plural speaker as depicted in the two examples below.

Example: I spent a lot of money on food at restaurants.

Example: I and David are very caring. We are very true friends.

2- Second Person Pronouns include "you" and used in referring to the addressee, in which "you" describes both the plural and singular addressee and includes both males and females as illustrated in the example below.

Example: If you come late, you will miss the class.

3- Third person pronouns comprise "he, she, it and they". This class of pronouns are used to indicate entities outside the speaker and addressee. He indicates singular masculine person, while she denotes singular feminine person. The pronoun "It" refers to inanimate entity. In addition, the pronoun "they" refers to plural animate and inanimate entity. The examples below illustrate the case of third person pronouns.

Example: Eric likes this course. He is a hard-worker.

Example: Tala likes languages. She will study Spanish at the university.

Example: Many students enrolled in English 1 courses. They are brilliant.

\subsection{Demonstrative Pronouns}

Demonstrative pronouns are defined as pronouns that are used to point at an object or thing. In Arabic, a demonstrative pronoun is a pronoun that refers to an actual referent, so that you as a speaker points at something, while talking about it. When the speaker says (this is nice), while pointing at a bird, so that includes two main elements; first, the intended meaning (the bird's body) and pointing at the body and the two things are inseparable. In addition, demonstrative pronouns in Arabic can be used to point at an abstract referent as saying (this is a difficult issue).

Demonstrative pronouns in Arabic are divided into two types according to the referent. The first type makes a distinction between demonstrative pronouns based on plurality and singularity such as (Tha, thalika, thi, thihi), demonstrative pronouns based on masculinity or femininity such as (Then, Thene, Tan and Ten, Aulaa) and demonstratives in terms of Animacy and inanimacy. 
Second, Demonstratives that make a distinction between pronouns according to the distance in which the referent is placed. Arabic uses the demonstrative pronouns (Hatha, Hathan, and Haula ) for near referent. In contrast, the demonstrative pronouns (Thalik, Thak, Tilka) are used for distant referent in Arabic. To get further insight into demonstratives in Arabic, let us consider the examples below.

Example: Thaka Alshuj'u Mahboub

- That courageous man is loved by all

Example: Hathan Alshuj'an Mahbubaan

- Those two courageous men are loved by all

Example: Aula'i aka Alshuj' an Mahbobuna

- Those courageous men are loved by all

In Arabic, there are two pronouns that can be used as demonstratives and adverbs simultaneously, namely (huna and thuma). Both pronouns cannot be used in the position of a subject or object. In Arabic, the prefix (ha) or the suffix (lik) are added to the adverb (huna), changing it to a demonstrative pronoun used to point at distant referent as in the example below

Example: Hahuna Iltaqytu Alaasdiqaa

- There, I met the friends.

Example: Hunalika raytu Mu'alimi

- There, I saw my teacher.

As for the (thuma), it is a demonstrative pronoun for distant referent and can only be suffixed by (Ta), changing it to (thamata) as in the example below

Example: Laysa Thamata Ahadun fe Albayt.

-There is nobody at home.

On the other hand, demonstrative pronouns in Spanish are employed to point at a person or an object and can appear in different forms, depending on their referent. Demonstrative pronouns in Spanish are divided into three types.

1- Demonstrative pronouns that are used to point at objects near the speaker as follows;

-Este is used for singular masculine objects as appears in the example below

Example: Este libro es interesante

- This book is useful

Esta is used for singular feminine objects as appears in the example below

Example 14: Esta chica es simpática

- This girl is nice

-(Estos) is used for plural masculine objects as appears in the example below

Example: Estos libros son interesantes

- These books are useful

Estas: is used for plural feminine objects as appears in the example below

Example: Estas chicas son simpáticas

- These girls are nice 
2- Demonstrative pronouns that indicate persons or objects near the addressee, which include the following

(Ese) for singular masculine referent as below

Example- Ese libro es interesante

- That book is useful

(Esa) for feminine singular referent as below

Example: Esa chica es simpática

- That girl is nice

(Esos) for Plural masculine referent

Example: Esos libros son interesantes

- These books are useful

(Esas) for Plural feminine referent as below

Example: Esas chicas son simpáticas

- These girls are nice

3- Demonstrative pronouns that indicate distant persons or objects from both the speaker and addressee, including (Aquel for singular masculine referent, Aquella for singular feminine referent, Aquellos for plural masculine referent and finally Aquellas for plural feminine referent) (Yotros, 2009).

As for demonstrative pronouns in English language, they are a class of deictic words that are used chiefly to specify a location of an entity, whether close or far from the speaker (Leech \& Svartvik, 2013). Demonstratives are also known as a group of words that that indicate an entity whether linguistically or physically (Crystal, 2008). English has four demonstrative words namely; this, that, these and those. The demonstrative "This" is used to indicate singular, near referent, while "these" is used to indicate plural distant referent. Furthermore, the demonstrative "That" is employed to point at singular distant entity. In contrast, "Those" is used to point at plural distant entity (Endley, 2010). Demonstratives are used in English language to perform many functions other than the above-mentioned functions as follows;

1- Demonstratives can be sued in English prior to nouns to describe entities.

Example: This blue car is not mine

Example: Those books will expand your knowledge

Example: Those beautiful flowers are my favorites.

2- Demonstratives can be used as pronouns in English

Example: I Picked red flowers. Those are my favorites.

Example: I bought a new yellow car. This is my preferable color.

3- Demonstratives can be used to introduce things

Examples: Hello. This is my cousin Tom

Example: Good. Morning. Those are my students, Carla and Lili.

In some cases, Demonstratives in English serve the function of anaphoric expression. Anaphora refers to the use of a pronoun or a similar expression in referring to a previously mentioned referent as in the example below.

Example. He stopped talking to me and that annoyed me 
In the example above, the demonstrative that is used as anaphoric expression, referring to (stopped talking). In addition, demonstratives are also used as cataphoric expressions, Cataphora is the use of pronouns or similar expressions in referring to a subsequent referent as in the example below.

Example: I like Those. Chocolate bars are my favorites.

\subsection{Relative Pronouns}

Relative pronouns are defined as pronouns that do not have meaning on their own but perform referential function in the context (Alzanad, 1993). The speaker uses relative pronouns in discourse so as to avoid speaking directly and to mitigate the effect of utterances on the addressee.

In Arabic, relative pronouns include the following; (Alathi, for masculine singular referent, Alati, for feminine singular referent, Alatani, for two feminine referents, Alathani, for two masculine referents, Alatheena, for plural masculine referents, Alawati or Alawa ai for plural feminine referents. The examples below provide extra insight into the use of relative pronouns in Arabic.

Example: Alrajulu Alathi Qabaltuhu Akhi

- The man who I met is my brother

Example Alfatatu Alati Tajlisu hunaka Tabibah

- The girl, who sits there is a doctor

Example: Alrijalu Alathena Zarunana bi Alams hum Asdiqa ai

- The men who visited us yesterday are my friends.

On the other side, Spanish uses relative pronouns to replace nouns and to connect two sentences, sharing the same noun. Relative pronouns in Spanish comprises (Que), which is used for animate and inanimate nouns as in the example below

Example: La chica que conocí ayer es de Córdoba

- The girl who I met yesterday is from Cordoba

- Quien, is used for animate nouns only and appears in two forms, singular (quien) and plural (quienes). The example below illustrates this case

Example: El hombre con quien estaba jugando es medico

- The man, who I was playing with, is a doctor

El que, which is used with animate and inanimate nouns and appears in four different forms (El que, la que, los que, las que) (Aragonés and Palencia, 2006)

The differences between those four forms are in terms of number and gender of referent appear in the example below.

Example: El chico con el que habla Maria es su hermano

- The boy, to whom Maria is talking, is her brother.

Comparing to English language, relative pronouns in English are defined as a set of lexical items used to describe the qualities and features of people and things. Relatives pronouns are utilized in English to introduce relative clauses. Three relative pronouns are distinguished in English language namely; who, which and that. The relative pronouns (who and that) are used in relative clauses to replace the subjective pronouns I, we, you, he, she, they). In addition, relative pronouns in English are also utilized to substitute for the objective pronouns (me, him, her, us and them) (Ritchards, 1998). The relative pronoun (who) is used where the referent noun is a human, in contrast, the relative pronoun (which) is used where the referent noun is non-human. While, the relative pronoun (that) can be used interchangeably with both human and non-human. The examples below elucidate the case of relative pronouns in English.

Example: The man who sits there is my uncle.

Example: The university from which I graduated is reputable. 
Example: The topic that you were talking about is fascinating.

\section{Conclusion}

This study conducts a comparison between three types of pronouns namely personal pronouns, demonstrative pronouns and relative pronouns. The comparison covers three languages; Arabic, Spanish and English. The results of the study indicate that numerous variations have been found in the use of pronouns in each language. Those variations are relevant to number of referents, gender and distance. The scope of this study is limited only to pronouns in Arabic, English and Spanish so that it is recommended future research to compare other grammatical structures among the three languages.

\section{References}

[1] Ibn Yaeish, M. (n.d). The detailed Explanation. Egypt. Alawqifyah Library.

[2] Al-Najjar, N. (2013). The communicative approach of linguistic study. Egypt. Horas international organization for publication.

[3] Alzanad, A. (1993). Structure of Text. Investigation of utterances in Context. Arabic Cultural Center.

[4] Aragonés, L. Palencia, R. (2006). Gramática de uso del español. Smele Madrid.

[5] Badis, N. (2009). Demonstratives in Arabic. Almanwieh. University Publication Center.

[6] Barakah, F. (1993). Roman Jacobson's Linguistic theory: Study and Texts. Beirut. University institution for studies and publications

[7] Cook, G. (1989). Discourse. Oxford University Press.

[8] Crystal, D. (2008). A Dictionary of Linguistics and Phonetics. Blackwell Publishing.

[9] Endley, M.J. (2010). Linguistic Perspectives on English Grammar. The United States of America: Information Age Publishing.

[10] Gardelle, L and Sorlin, S (2015). The pragmatics of personal pronouns. John Benjamins.

[11] Leech, G., \& Svarvic, J. (2013). A Communicative Grammar of English. Routledge.

[12] Ritchards, J. (1998). New interchange. English for international communication. Cambridge university press.

[13] Patrick, Charoudo, Dominique, Mulugo. (2002). Dictionary of Discourse Analysis. France. SEUIL; Sciences H.C.

[14] Taha, A. (1998). Tongue and scale. Arabic Cultural Center.

[15] Yotros, R. (2009). Gramática básica del estudiante de español. Spain. difusión Barcelona. 